\title{
Introduction to A Research Agenda for New Institutional Economics
}

\author{
Claude Ménard and Mary M. Shirley
}

When New Institutional Economics (NIE) first appeared on the scholarly scene in the early 1970s, it was a transformative movement. ${ }^{1}$ NIE aimed to radically alter orthodox economics by showing that institutions are multidimensional and matter in significant ways that can be statistically measured and systematically modeled. In the decades since, thousands of articles and books have pursued this premise and NIE has evolved from an upstart movement to a major influence on researchers in economics, political science, law, management, and sociology.

What made New Institutional Economics a radical idea was that it abandoned:

[...]the standard neoclassical assumptions that individuals have perfect information and unbounded rationality and that transactions are costless and instantaneous. NIE assumes instead that individuals have incomplete information and limited mental capacity and because of this they face uncertainty about unforeseen events and outcomes and incur transaction costs to acquire information. To reduce risk and transaction costs humans create institutions, writing and enforcing constitutions, laws, contracts and regulations so-called formal institutions - and structuring and inculcating norms of conduct, beliefs and habits of thought and behavior - or informal institutions. (Ménard and Shirley, 2005, p. 1)

The foundation of NIE stands upon Ronald Coase's seminal works, "The nature of the firm" (1937) and "The problem of social cost" (1960), which established the role of transaction costs in the emergence of firms and the importance of institutions in determining the level of transaction costs. Coase's ideas were neglected for a long time, but they began to bear fruit with the efforts of Oliver Williamson and Douglass North starting in the 1970s. Gradually, the founding thinkers, notably Ronald Coase, Douglass North, Elinor Ostrom, and Oliver Williamson, began to transform early intuitions about transactions, institutions, and property rights into powerful conceptual and analytical tools that attracted a rapidly growing group of researchers. Four Nobel prizes (Coase, North, Ostrom, and Williamson), strong policy impacts, increasing penetration of mainstream journals, and a growing body of adherents and research across many fields besides economics, all signal NIE's arrival as a successful movement (see Ménard and Shirley, 2014). The creation of

1 Williamson (1975) first coined the term New Institutional Economics. 
the International Society of New Institutional Economics (ISNIE) in 1997 (now the Society for Institutional \& Organizational Economics or SIOE) further solidified the institutionalization of NIE as a successful idea.

Today, NIE is at a crossroads. Research showing that institutions matter for growth, investment, welfare, or similar outcomes is now a crowded field. Younger scholars are searching for novel and less traveled directions to pursue. At the same time, the inactivity or death of many of the intellectual giants of the field have left younger researchers wondering how best to carry on their legacy and make their own contributions. Consequently, younger scholars often ask, where should I put my research efforts? What are the most important gaps in our knowledge of institutions? How are emerging technologies and new developments changing the frontier of institutional economics?

This volume provides guidance on how to move forward. Drawing on a diverse group of authors, most from a newer generation of institutionalists, 30 brief chapters explore priority issues for future NIE research. These short chapters aim to inspire scholars who are not experts in their subjects or in NIE itself to embark on studies of these priority issues. As we detail below, some chapters probe the frontiers of our knowledge of issues long at the forefront of NIE, while others search for emerging questions in topics underexplored by NIE. Another set scrutinizes areas where new technology and evolving circumstances raise novel issues. Concluding chapters deal with tools, techniques, and approaches, including how to measure institutions, use experiments, and exploit big data and machine learning. Although no one can know precisely where the frontier of inquiry lies and what new questions may suddenly arise, the chapters in this volume provide direction on how to seek that frontier and investigate unforeseen questions that may burst forth in the future.

The volume begins with two themes that were the foundational heart of NIE, reflecting the legacies of Douglass North and Oliver Williamson: government institutions (Part I) and contracts and organizations (Part II). While these themes have been the subjects of much exploration, there are still many unanswered questions. For example, collective action (Chapter 1 ) has been extensively researched, yet it still holds many mysteries about when norms promote cooperation, when political parties emerge around common interests, or why we see such variation across countries. Similarly, despite much research on federalism, regulation, and provision of public goods, Chapters 3, 4, and 5 find many unanswered questions worthy of greater attention. Not all government themes have been the subject of extensive study, however. While NIE has been preoccupied with the workings of democracy, there has been far less intellectual effort examining non-democracies, and Chapter 2 suggests many promising opportunities for new research on autocracies.

The situation is comparable in Part II. Despite an extensive literature on contracts, governance, and network industries, many questions remain. Thus, Chapter 6 points to many exciting opportunities to test empirically the vast theoretical literature on 
relational contacts, especially in developing countries, and Chapter 7 finds fascinating and underexamined issues around contracts between firms and creative agents in innovative industries. New research agendas have arisen in network industries with the advent of smart technologies that continually challenge earlier contractual relationships (Chapter 8). New research opportunities can also be found in transaction costs economics through a better understanding of how cognitive and contextual factors influence governance choice and ultimately transaction and firm performance (Chapter 9). And students of contracts will find novel research opportunities comparing public versus private contacts using new tools and a wealth of rich detail found in recently digitized data and other sources described in Chapter 10. Finally, the availability of microdata and experimental methods will enhance our understanding of transactions and transactors (Chapter 11).

Part III explores another core and well-explored field in NIE - laws and property rights. While seminal articles on formal laws and property rights are part of the NIE's foundation, starting with the pivotal contributions of Ronald Coase, there is ample room for new applications, new theory, and new empirical tests. Moreover, changes in technologies, circumstances, and demands mean that the issues are constantly evolving in varying ways across developed and developing countries. Drawing on the seminal works of Elinor Ostrom and other founding thinkers, the chapters in this section explore the novel research questions raised in the study of property rights in natural resources (Chapter 12) and the commons (Chapter 13), as well as issues of property rights and economic development (Chapter 14). Any consideration of law and property rights must also confront challenges to institutional theory posed by the extraordinary development of China in the absence of rule of law. A number of alternatives have substituted for rule of law in China, and Chapter 15 points to important research opportunities to explore the uses and limitations of these substitutes and whether and how much China can continue to develop without rule of law.

Norms, culture, and beliefs, the subject of Part IV, were much stressed by Douglass North, but have been far less studied than formal institutions. This is changing fast, as the revolution in computing power and digitization of social indicators, surveys, and details of social interactions has opened new ways to study these topics. The first three chapters consider the challenges of investigating internal, or what North termed informal, institutions (Chapter 16); the coevolution of institutions and culture (Chapter 17); and modeling the institutional matrix including the complexity of norms and culture (Chapter 18 ). Making progress on these major unknowns is a critical but daunting challenge for NIE research. Corruption, which lies at the intersection of formal institutions, norms, and culture, illustrates the difficulty and rewards of studying such issues. Chapter 19 calls for new research to address such critical questions as: how do cultures of corruption develop, and how can they be changed? And, how do anti-corruption interests organize politically to change the institutions that facilitate patronage and discretion, replacing them with meritocratic, formula-bound ones? Last, Chapter 20 turns to religion. Beliefs remain one of the frontier issues for NIE, yet, despite the importance of religion, 
there has been far less recent research on this and other kinds of beliefs than we might expect. The new research suggested in Chapter 20 would promote better understanding of the relationship between religion and economic growth and how the state interacts with religious organizations.

In Part V, the book turns to other areas underexplored by NIE, such as family and gender, and issues raised by the impact of new technology and changing environments on work, agriculture, finance, and media. These topics are at the frontier of NIE, and raise fundamental questions of how institutions adapt to rapidly changing circumstances. Strangely, NIE has neglected the transformation of marriage, divorce, and the role of women, yet there are many opportunities for rewarding and important research, outlined in Chapter 21. The dramatic changes in what it means to have a job or to go to work also poses exciting research opportunities (Chapter 22). Similarly, information technologies and climate change represent important challenges to agriculture, while the progress in modernizing agriculture in developed countries raises the fundamental question of why agriculture is synonymous with poverty in much of the rest of the world (Chapter 23). Many of the issues surrounding new technology are illustrated by blockchain, which records transactions in an open and decentralized ledger that purports to be tamper proof. Chapter 24 asks, is blockchain hype or a substitute for trust and third-party verification that will reduce transaction costs and remake the financial sector much as the Internet remade retail commerce? The fundamental questions of blockchain could apply to many innovations: can they escape from human error and duplicity and overcome the opposition of powerful forces supporting status quo institutions? Finally, Chapter 25, the last in this part, explores how new media differs from old media in important ways that raise many issues around fake news and the threat to confidence in established institutions.

The book concludes with Part VI on new approaches and tools, exploring novel ways to study institutions in the ancient economies of Rome and Greece (Chapter 26); challenges to measuring institutions (Chapter 27); the implications of datafication and big data for the study of institutions and organizations (Chapter 28); the use of experiments in understanding collective action (Chapter 29); and the challenge of recognizing and understanding institutional puzzles (Chapter 30). As researchers stand poised at the edge of their quest into new explorations, these chapters will provide invaluable guidance and roadmaps. For example, Chapter 27 contrasts the pros and cons of objective and subjective measures of institutions and suggests that subjective measures are indispensable to capture the complex reality of most institutions. Rather than scrap them we need to be more explicit in modeling the process underlying expert perceptions. Chapter 28 explores how data science techniques such as machine learning, text analysis, and sentiment analysis might push the frontier of analysis of institutional and organizational governance, and provides guidance to finding new sources and exploiting new data. The concluding chapter (Chapter 30) proposes an alternative approach to institutional puzzles. It argues that researchers should not dismiss puzzling behavior as inefficient, but rather view it as constrained efficient and ask, like Ronald Coase, how did this come about? 
It is an opportune moment to explore NIE's future research agenda. An explosive rise in computing power, combined with machine learning and rapid digitization of rich datasets, allow researchers to investigate empirically questions that could never be analyzed systematically before. This is especially important for NIE, where empirical analysis demands rich and complex institutional details. Simultaneously with this data revolution, new technologies and globalization are spurring changes in laws, norms, culture, and beliefs that create many opportunities for new discoveries. This book aims to help us seize the moment. We hope it will inspire scholars to probe the front lines of research with the same enthusiasm and curiosity that characterized the founders of New Institutional Economics. We are optimistic that the research generated in response to this volume will help keep the field of New Institutional Economics on the frontiers of knowledge.

\section{References}

Coase, R.H. (1937). “The nature of the firm.” Economia, 4(16), November.

Coase, R.H. (1960). “The problem of social cost.” The Journal of Law and Economics, 3, 1-44.

Ménard, C. and M.M. Shirley (eds) (2005). Handbook of New Institutional Economics. Dordrecht: Springer.

Ménard, C. and M.M. Shirley (eds) (2014). "The future of New Institutional Economics: From early intuition to a new paradigm." Journal of Institutional Economics, 10(4), 541-65.

Williamson, O.E. (1975). Markets and Hierarchies. Analysis and Antitrust Implications. New York: Free Press. 
Claude Ménard and Mary M. Shirley - 9781788112512 Downloaded from PubFactory at 04/26/2023 09:38:12AM via free access 